\section{The Effect of Ibuprofen on Women with Copper Intrauterine Device-Associated Heavy Menstrual Bleeding: A Prospective Cohort Study}

\section{Abstract}

Objective: The current study aims to evaluate the effect of ibuprofen on women with heavy menstrual bleeding associated with copper intrauterine devices (CuIUDs).

Study design: A prospective cohort study conducted at Assiut Woman's Health Hospital, Egypt, from October 2015 to September 2016 included women complaining of heavy menstrual bleeding with Cu-IUDs. Eligible women received $1200 \mathrm{mg}$ ibuprofen per day for 5 days starting from the first day of menses for three consecutive cycles. The primary outcome was the clinical response of ibuprofen. The secondary outcomes included the observation of its effect on uterine blood flow and the patient's quality of life. Multiple logistic regression was conducted to identify the potential predictors for responsiveness to ibuprofen.

Results: One hundred three patients $(80.5 \%)$ showed response to ibuprofen after three months of treatment. There was a significant decrease in the mean number of bleeding days and sanitary pads after ibuprofen treatment $(p=.000)$. The uterine blood flow was decreased obviously after 3 months following the treatment $(p=.000)$. The bleeding days, uterine volume and uterine pulsatility index were significant predictors for responsiveness to ibuprofen after 3 months of use ( $p=.003, p=.04, p=.002$; respectively).

Conclusion: Ibuprofen can effectively decrease the menstrual bleeding associated with Cu-IUDs. This effect may be secondary to the decrease in the uterine blood flow. Satisfactory response to ibuprofen could be anticipated in women with fewer bleeding days, smaller uterine volume and higher uterine pulsatility index at the beginning of treatment.

Keywords: Heavy menstrual bleeding; Ibuprofen; Intrauterine device; Uterine blood flow

\section{Ali MK, Abbas AM*, Yosef AH and Abdalmageed OS \\ Department of Obstetrics and Gynecology, Faculty of Medicine, Assiut University, Assiut, Egypt}

\section{*Corresponding author: Abbas AM \\ ” bmr90@hotmail.com}

Department of Obstetrics and Gynecology, Faculty of Medicine, Assiut University, Assiut, Egypt.

Tel: 201003385183

Citation: Ali MK, Abbas AM, Yosef AH, Abdalmageed OS (2018) The Effect of Ibuprofen on Women with Copper Intrauterine Device-Associated Heavy Menstrual Bleeding: A Prospective Cohort Study. J Contracept Stud Vol.3 No.1:2

\section{Introduction}

Copper intrauterine device (Cu-IUD) is considered one of the most commonly used methods of reversible contraception [1]. Pain and abnormal uterine bleeding are the most common reasons for the discontinuation of its use [2].

Excessive prostaglandin release appears to play an important role in provoking both bleeding and pain related to IUDs [3]. Prostacyclin is one of the prostaglandin metabolites that present in the endometrium causes vasodilatation and inhibits platelet aggregation. On the other hand, thromboxane induces vasoconstriction and blood clotting [4].

Non-steroidal anti-inflammatory drugs (NSAIDs) are prostaglandin synthetase inhibitors acting by decreasing production of endometrial prostaglandins; thus can improve both uterine bleeding and pain [5]. Since its discovery; several drugs in NSAIDs class have been used to treat heavy uterine bleeding and pain associated with IUD use such as mefenamic acid, ibuprofen and naproxen [6]. 
A recent systematic review reported that NSAIDs are the most widely studied drugs for reduction of the menstrual blood and pain associated with Cu-IUD [7]. The Cochrane Review also found that NSAIDs are the most effective treatment to reduce the bleeding with IUD use [8]. However; most of these studies looked at the clinical effect of NSAIDs on the heavy menstrual bleeding in Cu-IUDs users rather than studying their effect on uterine blood flow.

The current study aims to determine the efficacy of ibuprofen in treating the heavy menstrual bleeding associated with Cu-IUDs, and to test the hypothesis that ibuprofen exerts its clinical effect on the menstrual bleeding through remodeling of the blood flow to uterus.

\section{Materials and Methods}

The current study was a single-center, prospective cohort study (registered at ClinicalTrials.Gov; NCT02580344) compassing the effect of ibuprofen on Cu-IUDs associated heavy menstrual bleeding. The Assiut University Medical Ethical Review Board approved the study. We recruited the participants from the Family Planning Clinic during the period between the $1^{\text {st }}$ of October 2015 and the $30^{\text {th }}$ of September 2016. All eligible participants included in the study signed a written informed consent before participation after explaining the nature of the study.

We clinically evaluated all women who presented with complaints of heavy menstrual bleeding with Cu-IUDs and invited them to participate in the study. We considered the menstrual bleeding to be heavy if it lasts more than 7 days, patients' experience of flooding through clothes or bedding, need to change the tampon or pad after less than 2 hours, passage of blood clots, and/or if they needed double sanitary protection (tampons and towels) [9].

We included women aged between 20-45 years with, had regular cycles, planning for birth spacing for at least 6-12 months, with no history of any medical problem or drug intake, no contraindications for ibuprofen and had a normal pelvic examination.

We excluded women with evidence of anemia, defective coagulation, adnexal abnormality on ultrasound, history of hyperplasia in a previous endometrial biopsy, and history of allergy to NSAIDs. Finally, we excluded women either receiving any haemostatic medications, and those declines to utilize ibuprofen or to maintain the menstrual diary.

One of the study researchers approached all eligible women and collected the following data: age, parity, educational level, the mode of delivery and the type of inserted Cu-IUD. Then, he used the menstrual diary to evaluate the baseline menstrual blood loss (MBL). Finally, he clinically examined the patients to exclude general or local causes of heavy menstrual bleeding.

We conducted a transvaginal ultrasound (TV/US) in cycle day 2 using a Sonoline G60S ultrasound imaging system (Siemens, Germany) with 4-7 MHz endovaginal probe to assess the uterine volume and the adnexa. Then, we assessed the blood flow in the uterine and intramyometrial blood vessels by Doppler Ultrasound. Each uterine vessel was examined by a real-time spectral analysis color Doppler technique obtained immediately after getting from the hypogastric artery. The systolic/diastolic (S/D) ratio, resistance index (RI) and the pulsatility index (PI) of both uterine arteries as well as intramyometrial blood vessels were calculated when three similar consecutive waves appeared.

Finally, we asked all the participants to receive ibuprofen 1200 mg (Brufen; Abbott; Egypt) per day for 5 days starting from the first day of the cycle for the next three consecutive cycles [6]

The primary outcome measure was the clinical effect of ibuprofen on MBL in Cu-IUDs users after 3 months of treatment as measured by the monthly menstrual diary. The secondary outcomes included the effect of ibuprofen on uterine blood flow and the patient's quality of life with ibuprofen treatment.

All women were followed up monthly for 3 months. During each monthly visit; we evaluated the patients clinically by asking them to report their records of the menstrual diary. The study researcher instructed the patients how to fill it after inclusion in the study. We evaluated the uterine volume and the Doppler indices in both uterine arteries and intramyometrial blood vessels at cycle day 2 of the $3^{\text {rd }}$ month. The Health-Related Quality of Life4 (HRQoL-4) questionnaire was used at baseline and at 3 months to evaluate the quality of life with treatment. This questionnaire consists of 4 questions: health as self-assessed, the number of days feeling physically unhealthy, the number of days feeling mentally unhealthy, and "lost days". This means days when work or other daily activities are not possible [10].

The compliance of treatment was revised at each visit (by checking the empty tablet sites and asking them to report the side effects of ibuprofen). Ibuprofen failure was defined as failure of ibuprofen to control the heavy bleeding after 3 months of consecutive use [8].

We calculated the sample size using Open Epi-info software program. Previous study reported that ibuprofen decreased blood loss among Cu-IUD users by 25\% [11]. Based on our assumption that ibuprofen can cause reduction of $\mathrm{MBL}$ down to $50 \%$, a sample size of 128 patients should be recruited to detect a $25 \%$ difference [odds ratio $=3$ ] assuming a drop-out rate of $10 \%$, $\alpha$ of 0.05 and power of study at $80 \%$.

We collected the data and analyzed using SPSS software Chicago, IL, USA, version 21. Comparison between categorical variables in both groups was done by Chi-square test or Fisher's exact test if appropriate and continuous variables were compared using Student T-test. A paired-t test was used to compare continuous variables before and after ibuprofen treatment. We performed a multivariate linear regression model to assess if any baseline clinical or sonographic characteristics were associated with response to ibuprofen. We considered $p$-value $<.05$ as significant.

\section{Results}

We recruited 140 patients to participate in the study. Five patients preferred to remove of the IUD and seven patients 
decline participation in the study. At the end of study, we found that 103 patients $(80.5 \%)$ responded to treatment. However, the ibuprofen failed to control the bleeding in 25 patients (19.5\%); ten of them opted for IUD removal, while the remaining 15 women received tranexamic acid (Figure 1).

Table 1 shows the baseline characteristics of the study participants according to their clinical response after 3 months' treatment. Both groups, responders and non responders, were homogenous regard the baseline criteria with no significant differences.

Table 2 shows the differences in bleeding pattern in both groups at 3 months. There was a significant decrease in the number of bleeding days per month and number of sanitary pads per day besides significant increase in the number of bleeding free days in responders group $(p=.000)$. Moreover; the responders group had a smaller uterine volume, higher $\mathrm{PI}$ in both uterine and intramyometrial blood vessels $(p=.000)$.

Table 3 summarizes the bleeding pattern in the responders before and after 3 months of ibuprofen treatment. Collectively, the bleeding pattern was improved significantly after 3 months of ibuprofen treatment in the responders group $(p=.000)$ (Table 3). As regards the Doppler indices; S/D, RI and PI of the uterine arteries and intramyometrial blood vessels increased significantly from baseline to 3 months following ibuprofen treatment $(p=.000)$ (Table 4).

Table 5 shows that there was a significant improvement in the overall patients' reported health at 3 months in the responders group $(p=.000)$. In addition, there was a significant reduction in the number of days feeling physically or mentally unwell and a significant reduction in the number of lost days in responders group at 3 months

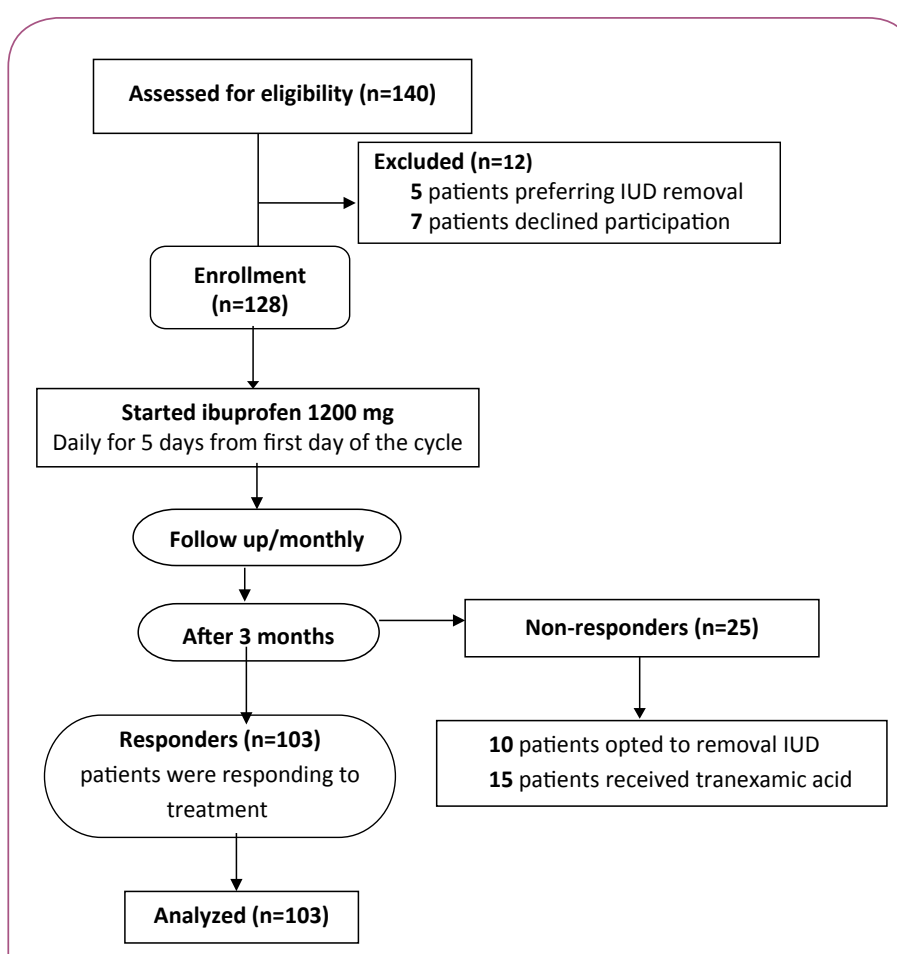

Figure 1 Flowchart of the study participants.
Table 1 The baseline characteristics of the study participants according to their clinical response after 3 months of ibuprofen treatment.

\begin{tabular}{|c|c|c|c|}
\hline Characteristics & $\begin{array}{l}\text { Responders } \\
(\mathrm{n}=103)\end{array}$ & $\begin{array}{l}\text { Non responders } \\
(n=25)\end{array}$ & P-value \\
\hline Age (years) & $33.90 \pm 6.8$ & $34.40 \pm 6.3$ & 0.32 \\
\hline \multicolumn{4}{|l|}{ Residence } \\
\hline Rural & $44(42.8)$ & $14(56.0)$ & \\
\hline Semiurban & $31(30.0)$ & $4(16.0)$ & 0.33 \\
\hline Urban & $28(27.2)$ & $7(28.0)$ & \\
\hline \multicolumn{4}{|l|}{ Education } \\
\hline Illiteracy & $52(50.4)$ & $16(64)$ & \\
\hline Read and write & $30(29.1)$ & $6(24)$ & \\
\hline Primary & $7(6.7)$ & 0 & \\
\hline Preparative & $2(1.9)$ & $1(4.0)$ & 0.67 \\
\hline Secondary & $6(5.8)$ & $1(4.0)$ & \\
\hline Academic & $6(5.8)$ & $1(4.0)$ & \\
\hline \multicolumn{4}{|l|}{ Employment } \\
\hline Housewife & $77(74.7)$ & $19(76.0)$ & 0.89 \\
\hline Employee & $26(25.3)$ & $6(24.0)$ & \\
\hline Parity & $2.6 \pm 1.2$ & $2.7 \pm 0.9$ & 0.16 \\
\hline Previous miscarriage & $21(20.3)$ & $7(28.0)$ & 0.43 \\
\hline $\begin{array}{l}\text { Previous caesarean } \\
\text { section }\end{array}$ & $28(27.1)$ & $5(20.0)$ & 0.41 \\
\hline $\begin{array}{l}\text { Duration from the last } \\
\text { delivery (month) }\end{array}$ & $18.77 \pm 17.2$ & $19.84 \pm 18.7$ & 0.86 \\
\hline Lactation & $20(19.4)$ & $7(28.0)$ & 0.08 \\
\hline BMI $\left(\mathrm{kg} / \mathrm{m}^{2}\right)$ & $24.2 \pm 3.3$ & $24.6 \pm 2.4$ & 0.62 \\
\hline \multicolumn{4}{|l|}{ Type of IUD } \\
\hline Copper T 380-A & $85(82.5)$ & $18(72.0)$ & \multirow{2}{*}{0.26} \\
\hline Multiload & $18(17.5)$ & $7(28.0)$ & \\
\hline $\begin{array}{l}\text { Duration of IUD use } \\
\text { (month) }\end{array}$ & $18.04 \pm 17.6$ & $16.32 \pm 15.8$ & 0.66 \\
\hline $\begin{array}{l}\text { Duration of heavy } \\
\text { bleeding (month) }\end{array}$ & $4.33 \pm 0.9$ & $4.40 \pm 0.8$ & 0.73 \\
\hline
\end{tabular}

Table 6 shows the logistic regression to identify predictors of responsiveness to ibuprofen. In multivariate analysis, the response to ibuprofen was associated with fewer number of bleeding days (OR [odds ratio] 4.06, 95\% Cl [confidence interval] $1.63-10.13, \mathrm{p}=.003$ ), smaller uterine volume (OR $1.12,95 \% \mathrm{Cl}$ $1.00-1.25, \mathrm{p}=.04)$ and higher uterine $\mathrm{PI}(\mathrm{OR} 0.01,95 \% \mathrm{Cl} 0.001-$ $0.22, p=.002)$.

\section{Discussion}

Contrary to most of previous studies, which investigated the clinical effect of NSAIDs in treating Cu-IUDs associated heavy menstrual bleeding; the current study is the first one that investigated the effect of ibuprofen treatment on MBL pattern and uterine blood flow in women complaining of heavy bleeding with Cu-IUDs.

The present work demonstrates that ibuprofen was effective regarding the outcomes of uterine bleeding profile with $\mathrm{Cu}$ IUDs. Furthermore, we demonstrated that ibuprofen treatment 
Table 2 The clinical and sonographic data of responders and non responders at 3 months of ibuprofen treatment.

\begin{tabular}{|c|c|c|c|}
\hline Variables & $\begin{array}{c}\text { Responders } \\
(\mathbf{n = 1 0 3 )}\end{array}$ & $\begin{array}{c}\text { Non responders } \\
(\mathbf{n = 2 5})\end{array}$ & P-value \\
\hline $\begin{array}{c}\text { Number of bleeding days } \\
\text { per month }\end{array}$ & $5.3 \pm 1.1$ & $9.2 \pm 0.76$ & .000 \\
\hline $\begin{array}{c}\text { Number of bleeding free } \\
\text { days }\end{array}$ & $23.8 \pm 2.2$ & $17.7 \pm 2.1$ & .000 \\
\hline $\begin{array}{c}\text { Number of sanitary pads } \\
\text { per day }\end{array}$ & $3.18 \pm 0.9$ & $5.85 \pm 0.95$ & .000 \\
\hline $\begin{array}{c}\text { Uterine volume } \\
\text { Uterine artery pulsatility } \\
\text { index }\end{array}$ & $45.66 \pm 5.6$ & $66.04 \pm 12.9$ & .000 \\
\hline $\begin{array}{c}\text { Intramyometrial pulsatility } \\
\text { index }\end{array}$ & $3.01 \pm 0.6$ & $1.60 \pm 0.52$ & .000 \\
\hline All data are presented as mean \pm standard deviation. & .000 \\
\hline
\end{tabular}

Table 3 The bleeding pattern before and after 3 months of ibuprofen treatment in the responders group.

\begin{tabular}{|c|c|c|c|}
\hline \multirow{2}{*}{ Study outcomes } & \multicolumn{2}{c}{ Responders $(\mathbf{n = 1 0 3 )}$} & P-value \\
\hline Number of bleeding days per month & $8.3 \pm 1.6$ & $5.3 \pm 1.1$ & .000 \\
\hline Number of bleeding free days & $18.95 \pm 2.8$ & $23.8 \pm 2.2$ & .000 \\
\hline Number of sanitary pads per day & $6.19 \pm 0.92$ & $3.18 \pm 0.9$ & .000 \\
\hline
\end{tabular}

Table 4 Uterine volume and Doppler indices before and after 3 months of ibuprofen treatment in the responders group.

\begin{tabular}{|l|c|c|c|}
\hline \multirow{2}{*}{ Outcomes } & \multicolumn{2}{c}{ Responders $(\mathrm{n}=\mathbf{1 0 3})$} & P-value \\
\hline Uterine volume $(\mathrm{ml})$ & $59.03 \pm 6.7$ & $45.66 \pm 5.6$ & .000 \\
\hline Uterine artery & & & \\
\hline S/D & $3.84 \pm 1.54$ & $5.15 \pm 1.95$ & .000 \\
\hline RI & $0.65 \pm 0.25$ & $0.88 \pm 0.05$ & .000 \\
\hline PI & $2.05 \pm 0.8$ & $2.90 \pm 0.70$ & .000 \\
\hline Intramyometrial blood vessels & & \\
\hline S/D & $3.08 \pm 0.80$ & $4.73 \pm 1.64$ & .000 \\
\hline RI & $0.67 \pm 0.14$ & $0.81 \pm 0.11$ & .000 \\
\hline PI & $2.37 \pm 0.8$ & $3.01 \pm 0.6$ & .000 \\
\hline
\end{tabular}

$\mathrm{S} / \mathrm{D}$; systolic/diastolic, $\mathrm{RI}$; resistant index, $\mathrm{PI}$; pulsatility index

Table 5 Changes in health-related quality of life using the HRQoL-4 questionnaire in the past 30 days after 3 months of ibuprofen treatment.

\begin{tabular}{|c|c|c|c|}
\hline \multicolumn{1}{|c|}{ Domains } & \multicolumn{2}{c|}{ Responders (n=103) } & P-Value \\
\hline Baseline & 3 months & \\
\hline Self-rated health good or excellent & $8(7.8)$ & $25(24.3)$ & .000 \\
\hline Number of days feeling physically unwell & $8.6 \pm 2.5$ & $3.4 \pm 1.9$ & .002 \\
\hline Number of days feeling mentally unwell & $7.9 \pm 1.7$ & $3.0 \pm 1.8$ & .001 \\
\hline Number of lost days (no regular activity) & $8.3 \pm 2.1$ & $2.5 \pm 1.6$ & .000 \\
\hline All data are presented as $n(\%)$ or mean \pm standard deviation. & \\
\hline
\end{tabular}

reduced the uterine volume and blood flow to and inside the uterus after 3 months of use, a change that could have been the cause of the effect of the treatment.

Heavy menstrual bleeding is reported by a considerable number of new Cu-IUDs users [12-14] that can result in iron deficiency anemia [15]. One of the most accepted mechanisms in explaining this phenomenon is that CU-IUD has been associated with an increase in the prostaglandin production which subsequently can cause an increase in the menstrual bleeding $[16,17]$. The implication of using ibuprofen was based on its ability to decrease prostaglandin production within the endometrium, an effect that leads to decrease the uterine bleeding with Cu-IUDs [18].

The NSAIDs are the most commonly tested medications for treatment of heavy bleeding with Cu-IUDs; not only for controlling the current bleeding attack but also as prophylactic against the uterine bleeding [19]. In the current study, we confirmed that ibuprofen is effective in reducing the amount of blood loss in the women complaining of heavy bleeding after Cu-IUDs insertion as $80 \%$ of them achieved a satisfactory response after 3 months. Similar to our finding, a Cochrane systematic review included 15 randomized controlled trials with more than 2700 women found that NSAIDs should be considered the first line for reducing bleeding associated with IUD insertion [8].

Most of previous studies relied on quantitative methods for assessment of MBL as alkaline hematin method [20] and pictorial blood loss assessment chart [21]. However; we used the menstrual diary, an easy method for assessment of MBL, to evaluate the uterine bleeding. The nature of our patients may be behind this because they need a simplified tool to understand the evaluation method.

In our study, ibuprofen was effective in decreasing the uterine volume after 3 months of treatment. We are in the same track with the previous studies that proved a significant decrease in the mean uterine volume may lead to obvious improvement of uterine bleeding as well as the pain associated with IUD $[22,23]$.

Many studies investigated the uterine blood flow in women using CU-IUD and showed that those who developed heavy bleeding might be due to decrease vascular resistance in the uterine artery, therefore they reported decreased Doppler indices in those women [24-27]. What is new in this study that we evaluated the intramyometrial blood vessels Doppler indices beside both uterine arteries, which was not studied. We considered the changes in these small blood vessels which penetrate deeply into the myometrium to perfuse it, as another marker for the effectiveness of ibuprofen. Our results revealed a significant decrease in the uterine arteries and intramyometrial blood flow in patients received ibuprofen for 3 months. Reduction in the uterine volume and decrease in the blood flow to and inside the uterus may stand behind the observed clinical improvement.

Table 6 Logistic regression for the variables independently associated with response to ibuprofen in treatment of CU-IUD associated heavy bleeding.

\begin{tabular}{|c|c|c|}
\hline Variables & OR (95\% Cl) & P-value \\
\hline Age & $(0.89-1.12)$ & 1.0 \\
\hline BMI & $1.12(0.92-1.35)$ & .27 \\
\hline Parity & $0.66(0.22-1.96)$ & .46 \\
\hline Duration of bleeding (month) & $1.25(0.67-2.33)$ & .48 \\
\hline Number of bleeding days & $4.06(1.63-10.13)$ & .003 \\
\hline Uterine volume (ml) & $1.12(1.00-1.25)$ & .04 \\
\hline Uterine pulsatility index & $0.01(0.001-0.22)$ & .002 \\
\hline Lactation & $0.23(0.006-9.71)$ & .23 \\
\hline
\end{tabular}

This article is available in: http://contraceptivestudies.imedpub.com/archive.php 
As mentioned before, $80.5 \%$ of our participants responded well to ibuprofen, on the other hand; $19.5 \%$ of women did not respond to treatment. However; the researchers could not find an accepted explanation to those who did not respond to NSAIDs. For this reason; we examined the value of baseline clinical and ultrasonographic criteria of the studied women in predicting the responsiveness to ibuprofen at 3 months follow up visit. We found that more of bleeding days, higher uterine volume and lower uterine artery $\mathrm{PI}$ are independently associated with poor response to ibuprofen in patients suffering from $\mathrm{Cu}$ IUD associated heavy bleeding.

Uterine volume as a predictor for the effectiveness of levonorgestrel releasing IUD in controlling bleeding and pain with adenomyosis was studied before in a recent study [28]. Our results were in agreement with this study which proved that failure of the treatment was associated significantly with a large volume uterus. Additionally; Hurskainen et al. [29] investigated

\section{References}

1 Winner B, Peipert JF, Zhao Q, Buckel C, Madden T, et al. (2012) Effectiveness of long-acting reversible contraception. N Engl J Med 366: 1998-2007.

2 Maguire K, Joslin-Roher S, Westhoff CL, Davis AR (2015) IUDs at One Year: Predictors of Early Discontinuation. Contraception 92: 575 577.

3 Andrade A, Wildemeersch D (2009) Menstrual blood loss in women using the frameless FibroPlant ${ }^{\circ}$ LNG-IUS. Contraception 79: 134-138.

4 Kouides PA, Byams VR, Philipp CS, Stein SF, Heit JA, et al. (2009) Multisite management study of menorrhagia with abnormal laboratory haemostasis: A prospective crossover study of intranasal desmopressin and oral tranexamic acid. Br J Haematol 145: 212-220.

5 Bradley LD, Gueye NA (2016) The medical management of abnormal uterine bleeding in reproductive-aged women. Am J Obstet Gynecol 214: 31-44.

6 Hubacher D, Reyes V, Lillo S, Pierre-Louis B, Zepeda A, et al. (2006) preventing copper IUD removals due to side-effects among first time users: placebo-controlled randomized trial to study the effect of prophylactic ibuprofen. Human Reprod 21: 1467-1472.

7 Godfreya EM, Folgera SG, Gary Jenga, Jamiesona DJ, Curtisa KM (2013) Treatment of bleeding irregularities in women with coppercontaining IUDs: a systematic review. Contraception 87: 549-566.

8 Grimes DA, Hubacher D, Lopez LM, Schulz KF (2006) Non-steroida anti-inflammatory drugs for heavy bleeding or pain associated with intrauterine-device use. Cochrane Database Syst Rev. CD006034.

9 Royal College of Obstetricians and Gynecologists (2014) Advice for Heavy Menstrual Bleeding (HMB) Services and Commissioners November RCOG.

10 Shaaban MM, Zakherah MS, El-Nashar SA, Sayed GH (2011) ow dose combined oral contraceptive pills for idiopathic menorrhagia: a randomized clinical trial. Contraception 83: 48-54.

11 Roy S, Shaw ST Jr (1981) Role of prostaglandins in IUD-associated uterine bleeding - effect of a prostaglandin synthetase inhibitor (ibuprofen). Obstet Gynecol 58: 101-106. the relation between $\mathrm{PI}$ and menorrhagia and found that women with lower uterine flow resistance bleed more [29].

The strengths of our study include that it was a prospective cohort study with calculated sample size for achieving sufficient power to detect a clinically significant difference in our primary outcome. The studying of ibuprofen effect on uterine blood flow in women complaining of heavy bleeding with Cu-IUDs and identification of potential predictors for responsiveness to ibuprofen had not studied before.

In conclusion, Ibuprofen can effectively control the blood loss associated with Cu-IUDs. The decrease in uterine volume and the increase in uterine blood flow resistance may be behind the treatment effect. However; the fewer bleeding days, smaller uterine volume, higher uterine artery PI could satisfactory predict ibuprofen effect on controlling heavy menstrual bleeding with Cu-IUDs.

12 Intrauterine devices: an effective alternative to oral hormonal contraception (2009) Prescrire Int 18: 125-130.

13 Forthofer KV (2009) A Clinical Review of the Intrauterine Device as an Effective Method of Contraception. J Obst Gynecol Neonat Nursing 38: 693-698.

14 Fouda UM, Yossef D, Gaafar HM (2010) Uterine artery blood flow in patients with copper intrauterine device-induced abnormal uterine bleeding. Middle East Fertility Society J 15: 168-173.

15 Fernandez XT, Young B, Lavin P, Baeza R, Seaman V (1980) The IUD and anemia: a study of hematocrit. Contracept Deliv Syst 1: 49-53.

16 Li W, Cao L, Chen Z, Li W, Du Q, et al. (2002) Study on the effects of FCu-IUD and FICU-IUD on matrix metalloproteinases in human uterine flushing and endometrium. J Huazhong Uni Sci Technolog Med Sci 22: 9-11.

17 Zhang JY, Luo LL (1992) Intrauterine device-induced menorrhagia and endometrial content of prostacyclins. Zhonghua Yi Xue Za Zhi 27: 167-168.

18 Friedlander E, Kaneshiro B (2015) Therapeutic Options for Unscheduled Bleeding Associated with Long-Acting Reversible Contraception. Obstet Gynecol Clin North Am 42: 593-603.

19 World Health Organization (2004) Selected practice recommendations for contraception use. (2nd edn.), Geneva: WHO.

20 Mercorio F, De Simone R, Di Carlo C, Bifulco G, Tessitore G, et al. (2003) Effectiveness and mechanism of action of desmopressin in the treatment of copper intrauterine device-related menorrhagia: a pilot study. Human Reprod 18: 2319-2322.

21 Sayed GH, Zakherah MS, El-Nashar SA, Shaaban MM (2011) A randomized clinical trial of a levonorgestrel-releasing intrauterine system and a low-dose combined oral contraceptive for fibroidrelated menorrhagia. Int J Gynaecol Obstet 112: 126-130.

22 Shaaban OM, Ali MK, Sabra AM, Abd El Aal DE (2015) Levonorgestrelreleasing intrauterine system versus a lowdose combined oral contraceptive for treatment of adenomyotic uteri: a randomized clinical trial. Contraception 92: 301-7. 
23 Cho S, Nam A, Kim H, Chay D, Park K, et al. (2008) Clinical effects of the levonorgestrel-releasing intrauterine device in patients with adenomyosis. Am J Obstet Gynecol 198: 373.e1-7.

24 Momtaz M, Zayed M, Rashid K, Idriss O (1994) Doppler study of the uterine artery in patients using an intrauterine contraceptive device. Ultrasound Obstet Gynecol 4: 231-234.

25 Frajndlich R, von Eye Corleta H, Frantz N (2000) Color Doppler sonographic study of the uterine artery in patients using intrauterine contraceptive devices. J Ultrasound Med 19: 577-579.

26 de Souza MAM, Geber S (2006) Doppler Color Flow Analysis of the Uterine Arteries Before and After Intrauterine Device Insertion A Prospective Study. J Ultrasound Med 25: 153-157.
27 Yigit N, Kacar M, Yigit H, Kosar P, Kosar U (2009) The effects of copper contraceptive intrauterine device on the uterine blood flow: A prospective transvaginal Doppler study. J Clin Ultrasound 37: 380384.

28 Lee KH, Kim JK, Lee MA, Ko YB, Yang JB, et al. (2016) Relationship between uterine volume and discontinuation of treatment with levonorgestrel-releasing intrauterine devices in patients with adenomyosis. Arch Gynecol Obstet 294: 561-566.

29 Hurskainen R, Teperi J, Paavonen J, Cacciatore B (1999) Menorrhagia and uterine artery blood flow. Hum Reprod 14: 186-189. 